\title{
Comparative assessment of epifluorescence microscopy, flow cytometry and solid-phase cytometry used in the enumeration of specific bacteria in water
}

\author{
Karine Lemarchand, Nathalie Parthuisot, Philippe Catala, Philippe Lebaron*
}

Observatoire Océanologique, Laboratoire ARAGO, Université Pierre et Marie Curie (Paris 6), Institut National des Sciences de l'Univers (INSU) CNRS-UMR-7621, BP 44, 66651 Banyuls-sur-Mer Cedex, France

\begin{abstract}
Rapid microbiology and the detection of rare events are important challenges in various fields of aquatic microbiology. Epifluorescence microscopy, flow cytometry and solid-phase cytometry are techniques used for direct methods in microbiology but the range of application of these different instruments is not clearly defined. In this study, we examined the lower limit of bacterial concentration to which each technique can be reliably used. Techniques were compared for the enumeration of (1) fluorescent beads, (2) labeled bacteria at different ratios of labeled/non-labeled cells, (3) Escherichia coli O157:H7 cells inoculated at different densities in tap water, and (4) E. coli O157:H7 cells in artificially contaminated natural seawater. The different methods gave results that correlated well despite the presence of a significant background of unlabeled cells. However, solidphase cytometry was the only technique that allowed the accurate enumeration of rare events (down to 1 cell) providing the same sensitivity as traditional culture methods. The detection sensitivity was not affected by the presence of up to $10^{7}$ unlabeled cells on the filter. In contrast, flow cytometry was a very rapid and accurate method but it could not be applied to the detection of rare events. E. Coli O157:H7 cells could be detected rapidly and accurately in environmental water samples in the presence of non-specific bacteria. Solid-phase cytometry combined with taxonomic probes allowed rapid and accurate detection of a large variety of species of ecological interest in a wide variety of aquatic environments.
\end{abstract}

KEY WORDS: Range of application · Epifluorescence microscopy · Flow cytometry · Rare events · Solid-phase cytometry $\cdot$ Specific bacteria

Resale or republication not permitted without written consent of the publisher

\section{INTRODUCTION}

Culture methods traditionally used in bacteriology have limitations from both quantitative and qualitative points of view. Although these techniques allow the detection of a single bacterium, amplification of the signal is required through growth of a single cell into a colony on a plate. This process is time-consuming and often requires from $24 \mathrm{~h}$ to $14 \mathrm{~d}$ of incubation before results are available. In most industrial and environmental applications, culture techniques are used to

*Corresponding author. E-mail: lebaron@obs-banyuls.fr quantify viable bacteria using non-selective or selective media. However, when applied to the detection of specific bacteria (e.g., species of ecological interest, pathogens, etc.) in the natural environment, mediabased methods can be inaccurate because of their selective nature. Microbial ecologists need direct and accurate methods for the detection and enumeration of specific microorganisms in aquatic systems, and for these reasons, developments in this area have been a topic of intense research over the last 2 decades. The challenge has been to find methods that combine a universal application, the assessment of viability, the potential to use taxonomic markers and the ability to detect low numbers of cells. 
A wide variety of methods has been developed to analyze the viability of individual cells as well as to detect specific populations (for reviews, see Amann et al. 1995, McFeters et al. 1995, Porter et al. 1997, Kell et al. 1998, Joux \& Lebaron 2000). Most of these methods are based on the detection of fluorescence and require specific instrumentation. Epifluorescence microscopy (EFM) and flow cytometry (FCM) are commonly used but neither technique is suited to the detection of rare events. This is probably one of the main limitations to the development of direct analytical methods alternative to culture.

The Chem Scan ${ }^{\mathrm{TM}}$ system (Chemunex, Ivry, France) is a recently developed solid-phase cytometer that uses direct fluorescent labeling of viable microorganisms in combination with an automated detection and counting system. This system can also be applied to the detection of specific bacteria when combined with the use of taxonomic probes such as fluorescent antibodies (Pyle et al. 1999). The solid-phase cytometer has been proposed as a tool to enable the very rapid detection of rare events in many different products and as an alternative to traditional plate counts. However, although solid-phase cytometry (SPC) was already successful in detecting rare events (Mignon-Godefroy et al. 1997, Reynolds \& Fricker 1999), it is important to evaluate the accuracy of cell counts provided by SPC by reference to well-known techniques such as FCM and EFM. Furthermore, a comparison of the detection limits of each instrument should be very useful for microbiologists to define which instrument is the most appropriate to their applications.

In this study, we examined the quantitative lower limit to which SPC (ChemScan $\left.{ }^{\mathrm{TM}}\right), \mathrm{EFM}$ and FCM could be reliably used and determined the quantitative range of application of these techniques. Initially, each technique was applied to the quantification of fluorescent microspheres at different densities (independent of the volume to be filtered) and concentrations (which combine densities and volumes filtered). Subsequently, these techniques were applied to the detection of a wide variety of fluorescent bacterial cell numbers with or without a background of non-fluorescent cells. Finally, the 3 techniques were applied to the specific detection of an enteric pathogen, Escherichia coli O157:H7, in artificially contaminated waters to assess the ability of each instrument to detect and enumerate specific bacteria in natural waters.

\section{MATERIALS AND METHODS}

Fluorescent microspheres and bacteria. Fluorescent microspheres (1 $\mu \mathrm{m}$ diameter; yellow-green fluorescent, standard $\mathrm{M}$ ) were provided by Chemunex.
For enumeration of bacterial cells, Escherichia coli (ATCC 8739) and E. coli O157:H7 (CIP 103571) were used. Cells were grown to stationary phase in trypticase soy broth (bioMérieux, Marcy-l'Etoile, France) and incubated at $30^{\circ} \mathrm{C}$ in the dark on a rotary shaker operating at $100 \mathrm{rpm}$. An overnight culture of E. coli ATCC 8739 was used to prepare fluorescent and nonfluorescent cells and an overnight culture of $E$. coli O157:H7, fixed with $2 \% \mathrm{w} / \mathrm{v}$ formaldehyde, was used to inoculate tap water and seawater at different densities ( 1 to $10^{6}$ cells) corresponding to concentrations ranging from 1 to $10^{6}$ cells $100 \mathrm{ml}^{-1}$. Strain ATCC 8739 was stained with a nucleic acid dye and used when a specific marker was not required for the experiments. Inversely, when needed strain O157:H7 was labeled with a fluorescent-specific antibody and chosen because of its public health significance. Fluorescent cells of E. coli ATCC 8739 were prepared by staining the cells with SYBR Green II dye (Molecular Probes, Eugene, OR, USA) (Lebaron et al. 1998). Cells were stained with a $10^{-4}$ dilution of a SYBR Green II stock solution (concentration not provided by the manufacturer) in the presence of $30 \mathrm{mM}$ potassium citrate and incubated for $30 \mathrm{~min}$. All incubations were at room temperature in the dark. Then, the cells were harvested and rinsed twice, and the working suspension of fluorescent cells was prepared by resuspending the cells in sterile physiological water $(0.9 \%$ $\mathrm{NaCl}$ ). The working suspensions of non-fluorescent cells were prepared by harvesting and rinsing the cells from an overnight culture.

Dilutions of fluorescent beads. The concentration of beads in the stock suspension was determined by FCM and EFM. Both enumerations were in good agreement (no significant difference between mean counts, $t$-test not shown) and the mean number of beads was used to estimate the theoretical number of beads in each dilution. Beads were serially diluted in $0.22 \mu \mathrm{m}$ pore-size filtered (Millipore type GS) autoclaved physiological water in order to obtain a large range of bead concentrations. The number of beads analyzed varied from 1 to $10^{7}$. The volume of a given dilution collected to obtain a given number of beads in the sample was calculated from the dilution factor and the bead concentration was determined from stock suspension. Bead counts were then compared by using the 3 instruments. Five replicates of each sample were analyzed. After analysis, the number of beads was calculated per $\mathrm{ml}$ of the stock solution and then submitted to statistical analysis (see below).

Preparation of fluorescent/non-fluorescent cell ratios. The concentrations of fluorescent and non-fluorescent cells in each stock suspension were determined as previously described for beads. First, the 3 instruments were compared following the same pro- 
tocol as that used for beads. Then, according to the type of experiment, SYBR Green II-labeled cells were analyzed alone or mixed with unlabeled cells. The cells were always mixed in a tube before filtration or FCM analysis. Fluorescent cells in the presence of different concentrations of non-fluorescent cells were enumerated within the analysis range of each instrument, which was previously determined from the counting of fluorescent beads. For SPC, densities corresponding to $1,10,10^{2}, 10^{3}$ and $10^{4}$ cells were analyzed in the presence of 0 to $10^{8}$ nonfluorescent cells. For EFM the numbers of fluorescent cells varied from 0 to $5 \times 10^{5}$ in the presence of 0 to $10^{8}$ unlabeled cells. The numbers of labeled cells used for FCM ranged from 0 to $10^{5}$ fluorescent cells in the presence of 0 to $10^{8}$ non-fluorescent cells. Five replicates were analyzed at each ratio. After analysis, the number of cells was calculated per $\mathrm{ml}$ of the stock solution and then submitted to statistical analysis (see below).

Detection of Escherichia coli 0157:H7 in environmental water samples. The concentration of autochthonous microflora in natural waters and the concentration of Escherichia coli O157:H7 in the stock suspension were determined by staining an aliquot of each sample with SYBR Green II (see above). After $30 \mathrm{~min}$ of staining, these samples were analyzed by FCM. Water samples (i.e., tap water and seawater) were fixed with $2 \%$ formaldehyde (final concentration) to prevent cell division of autochthonous bacteria, before diluting the stock suspension of E. coli O157:H7 to obtain a concentration of $10^{7} \mathrm{E}$. coli cells $100 \mathrm{ml}^{-1}$ of water. This suspension was then serially diluted in fixed tap water or seawater in order to obtain concentrations of $1,10,10^{2}, 10^{3}, 10^{4}, 10^{5}$ and $10^{6} \mathrm{E}$. coli cells $100 \mathrm{ml}^{-1}$. All dilutions were made in fixed water to maintain the concentration of autochthonous bacteria in all samples with different concentrations of $E$. coli. With regard to the detection limits obtained from tap water analyses, E. coli cells were detected in seawater by SPC only at concentrations of 1, 10 and 100 cells $100 \mathrm{ml}^{-1}$ corresponding to the volume routinely analyzed for water quality assessment. For FCM, the detection was performed at 2 concentrations $\left(10^{3}\right.$ and $10^{4} \mathrm{cells} \mathrm{ml}^{-1}$ ) corresponding to the range of application of this technique as determined from tap water analysis. Five replicates were analyzed at each concentration.

For SPC and EFM, each sample was filtered through a black polyester membrane $(25 \mathrm{~mm}$ diameter, $0.40 \mu \mathrm{m}$ pore-size; Chemunex) before transfer onto a $100 \mu \mathrm{l}$ drop of phosphate-buffered saline (PBST; $65 \mathrm{mM}$ sodium chloride, $10 \mathrm{mM}$ sodium phosphate buffer, $0.1 \%$ Tween $20,1 \%$ counter staining buffer [Chemunex] and $3 \%$ bovine serum albumin [pH 7.2]) contain- ing a 1:500 solution of fluorescein isothiocyanateconjugated O157 antibody (Kirkegaard \& Perry Laboratories, Gaithersburg, MD, USA). The PBST buffer was previously filtered through $0.22 \mu \mathrm{m}$ pore-size filters (Millipore type GS) and autoclaved. For seawater analysis, the membranes were pre-incubated for $3 \mathrm{~h}$ at $4^{\circ} \mathrm{C}$ onto a labeling pad (Chemunex) saturated with absolute methanol before being transferred onto the staining solution. This pre-incubation was necessary to eliminate the background fluorescence induced by the presence of phytoplanktonic cells (e.g., cyanobacteria) (Anderson et al. 1999). Membranes were incubated for $1 \mathrm{~h}$ at $37^{\circ} \mathrm{C}$ in a humidity chamber. The membrane filter was then mounted on a glass microscope slide or on a metallic holder for microscopic and SPC analysis, respectively.

For FCM, cells were stained in solution using the same concentration of fluorescein isothiocyanate-conjugated $\mathrm{O} 157$ antibody in PBST buffer and incubated for $1 \mathrm{~h}$ at $37^{\circ} \mathrm{C}$ in the dark. For seawater samples, we used the plot of green fluorescence (FL1) versus red fluorescence (FL3) to distinguish photosynthetic prokaryotes from non-photosynthetic prokaryotes.

In all cases, the concentration of the stock suspension of Escherichia coli O157:H7 cells was determined by FCM. The concentration of cells stained with SYBR Green II was compared with that obtained by the immunofluorescent staining procedure in order to validate the use of both procedures for cell counting.

Preliminary experiments have shown that the use of different staining procedures, including staining before and after filtration, had no effect on the staining efficiency in terms of both fluorescence intensity and cellular counts (data not shown).

FCM. FCM counts were performed with a FACSCalibur flow cytometer (Becton Dickinson) equipped with an air-cooled laser providing $15 \mathrm{~mW}$ at $488 \mathrm{~nm}$ and the standard filter setup. All parameters were collected as logarithmic signals. Green fluorescence was collected in the FL1 channel $(530 \pm 15 \mathrm{~nm})$. Cells were enumerated during a fixed time ( $5 \mathrm{~min}$ ) at a given flow rate calibrated at the beginning and at the end of each analysis session. Yellow-green fluorescent microspheres $(0.95 \mu \mathrm{m}$ diameter fluorescent size-standard beads; Polysciences Inc., Warrington, PA, USA) were systematically added to each sample as an internal reference. This internal standard allowed the normalization of cell fluorescences, which were expressed in bead fluorescence units.

EFM. EFM counts were performed on an Olympus Provis AX-70 microscope. Microscopic counts were determined following the procedure described by Lebaron et al. (1994). A minimum of 400 events was counted for each filter and at least 30 microscopic fields were analyzed. 
SPC. Each sample was vacuum-filtered onto $25 \mathrm{~mm}$ diameter, $0.40 \mu \mathrm{m}$ pore-size polyester membranes (Chemunex). The ChemScan ${ }^{\mathrm{TM}}$ laser scanning device has been described elsewhere (Mignon-Godefroy et al. 1997). The fluorescence emission was collected in the green channel (500 to $530 \mathrm{~nm}$ ).

Two procedures of discrimination between bacteria and background were used. The first used an automatic validation. The signals were analyzed with the MatLab-based software (Matworks, Natick, MA, USA) for comparison with Gaussian curves and discriminated (Mignon-Godefroy et al. 1997). A set of discriminants was applied to all fluorescent events detected after scanning the entire surface of the membrane, which then allows the differentiation of labeled microorganisms from autofluorescent particles present in the sample. At the end of the analysis procedure, the exact position of each detected cell on the membrane was displayed; this spatial information can be used to drive the motorized stage of the microscope allowing immediate visual result confirmation by EFM. All events positively selected after the discrimination process are validated by microscopic examination (Mignon-Godefroy et al. 1997), as true positive or false positive.

In addition, when this automatic discrimination procedure was not used, all detected fluorescent events including background signals were counted by the cytometer and were then manually discriminated under the microscope using the motorized stage as described above. The 2 procedures were applied to all experiments and data were used to compare the counts obtained by SPC using the automatic validation procedure with those obtained using a manual validation step.

Statistical comparison. The mean numbers of beads and cells were determined from 5 replicates and mean values were compared by Student's t-test using Statview software (SAS Institute Inc., Cary, NC, USA) working on a G3 Macintosh computer.

\section{RESULTS}

\section{Reproducibility among the staining procedures}

The reproducibility of counts was investigated by comparing FCM counts of Escherichia coli O157:H7 cells stained with both SYBR Green II and immunofluorescent procedures. No significant difference $(t$ test, $\mathrm{p}>0.05$ ) was observed, suggesting that both methods are efficient for cell counting (data not shown). Therefore, the immunofluorescent procedure was used when E. coli O157:H7 cells were detected in the presence of non-specific cells, whereas SYBR
Green II staining was preferred for cell counting in pure culture and for total cell counts in water samples. When possible, the SYBR Green II staining procedure was used because the staining protocol is fast and simple.

\section{EFM}

Bead counts. EFM was applicable in the range $10^{4}$ to $5 \times 10^{5}$ fluorescent beads. Analysis of bead numbers lower than $10^{4}$ beads by EFM was difficult because this concentration corresponded to approximately 1 bead per microscopic field.

Cell counts at different concentrations of unlabeled cells. The range of application was the same as that previously observed for bead counts with or without up to $10^{8}$ non-fluorescent cells. However, the presence of $10^{8}$ non-fluorescent cells on the filter was the upper limit since the cells covered the entire surface of the filter. The same results were obtained for enumeration of specific cells in water samples.

\section{FCM}

Bead counts. FCM was applicable in the range 1 to $2.5 \times 10^{6}$ fluorescent beads $\mathrm{ml}^{-1}$. This maximum limit corresponds to the detection of $5 \times 10^{5}$ beads because each FCM analysis was performed during 5 min at a

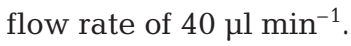

Cell counts at different concentrations of unlabeled cells. FCM was applicable to the detection of 100 labeled cells when the background of nonlabeled cells was up to $10^{8}$ cells. This minimum detection limit (100 cells) was higher than that previously determined for bead counts (1 bead). This difference was due to the fact that calibrated fluorescent beads were detected within a well-known and defined gate on the cytogram, whereas fluorescence and scatter signals of bacteria are more heterogeneous and their detection requires the analysis of at least 100 cells to be detected on the cytogram. The maximum limit was the same as that observed for bead counts.

Specific cell counts in natural waters. In contrast to the previous results, the detection of 100 Escherichia coli O157:H7 cells was not possible in either tap water or seawater. Therefore, this difference is more likely to be due to the presence of an important background of non-specific signals originating from natural waters. The minimum limit of FCM for specific cell counts in tap water was 1000 E. coli O157:H7 cells. Similarly, it was possible to detect 1000 and 10000 cells in seawater. 


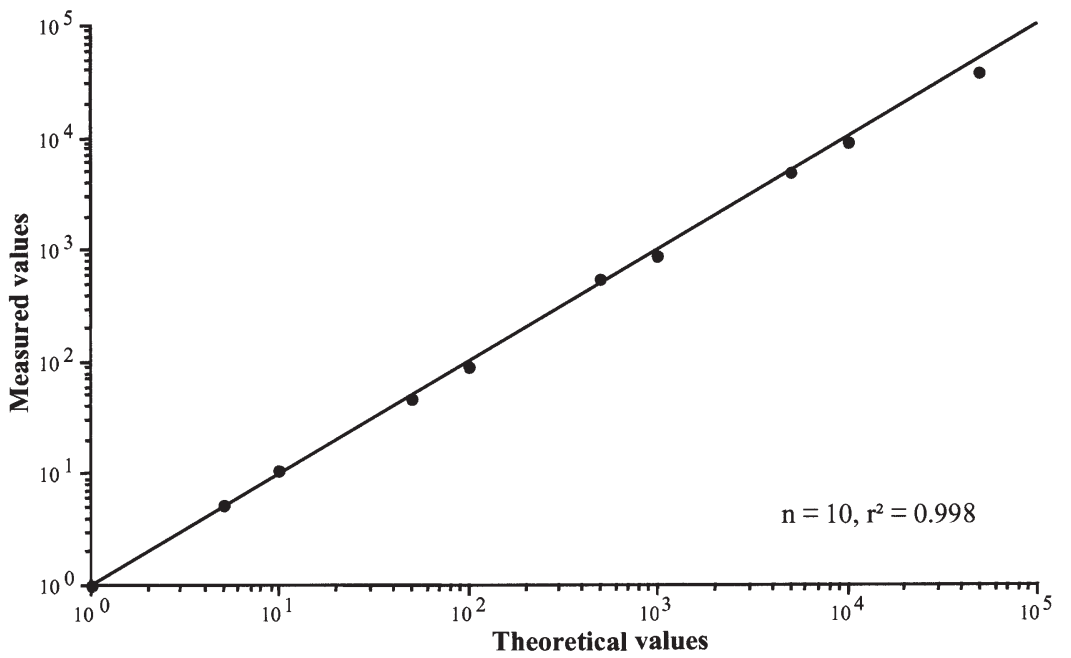

Fig. 1. Correlation between theoretical and measured counts of fluorescent beads as determined by solid-phase cytometry at different densities

\section{Comparison of counts obtained by EFM, FCM and SPC}

Bead counts were compared for a large range of bead numbers (1 to $\left.10^{7}\right)$. The theoretical values calculated from the concentration of beads in the stock solution and consequently in serial dilutions were well correlated with those measured by SPC within a wide range of bead numbers (Fig. 1). Because of the previous results, FCM and SPC counts could only be compared in the range of 1 to $5 \times 10^{4}$ beads. Counts were highly correlated, although correlation across 5 orders of magnitude facilitates high $\mathrm{r}^{2}$ values (n $=8, r^{2}=0.998$ ) (Fig. 2). Comparison between EFM and FCM was only possible in the range $10^{4}$ to $5 \times 10^{5}$ beads because of the respective detection

SPC

Automatic validation of counts by SPC. A good correlation was found between the automatic validation procedure and the manual validation step, suggesting that the automatic discrimination procedure of the instrument was good enough to be used ( $\mathrm{n}=124, \mathrm{r}^{2}=$ 0.997) (data not shown).

Bead counts. SPC was applicable in the range 1 to 5 $\times 10^{4}$ fluorescent beads. More than $5 \times 10^{4}$ beads were not detectable by SPC because the counting procedure generally aborted due to excessive data.

Cell counts at different concentrations of unlabeled cells. As previously observed for bead counts, SPC was able to detect down to a single cell with or without a high background of non-labeled cells (up to $10^{8}$ cells).

Specific cell counts in natural waters. As expected from the results obtained in the first experiment, SPC was the only system able to detect down to a single cell within a background of up to $10^{7}$ non-targeted cells. The results show that a single Escherichia coli cell is detectable by SPC independently of the volume of tap water filtered on the membrane and, consequently, independently of the number of non-labeled cells (see Fig. 3).

In seawater it was possible to detect 1, 10 and 100 cells in the presence of autochthonous bacteria. In this case, a single Escherichia coli cell was easily detectable by SPC in the presence of $1.6 \times 10^{8}$ nonspecific bacteria in $100 \mathrm{ml}$. However, this analysis was only possible when natural seawater was pre-treated by methanol to remove the fluorescence of phytoplanktonic cells. This treatment had no effect on the labeling of $E$. coli cells (data not shown). limits of these instruments. In this range, the correlation of counts was exceedingly good $\left(n=5, r^{2}=\right.$ 0.999) (data not shown). Then, the mean concentration of beads in the working solution was determined from the counts obtained by each method and at each bead density. The equality of mean values determined at different densities was then tested by combining the different instruments. When the comparison was possible, the equality of counts was accepted, suggesting that each technique provides accurate counts at densities within its respective range of application (Table 1). When 2 or 3 methods

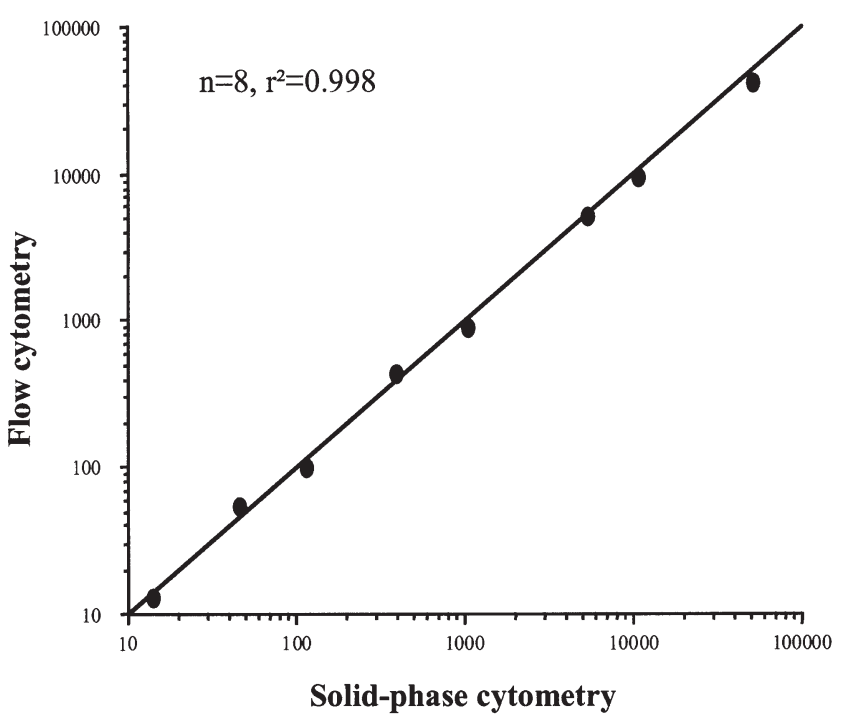

Fig. 2. Correlation between flow cytometry and solid-phase cytometry counts of fluorescent beads at different densities 
Table 3. Statistical comparison of mean concentrations $(\mathrm{n}=5)$ of Escherichia coli O157:H7 cells estimated from cells counts determined with each instrument and at 2 cell densities. Values are $t$ values determined from the paired $t$-test, and associated probabilities (no significant difference determined at ${ }^{*} \alpha=0.01$ ) are reported in parentheses

\begin{tabular}{|lccc|}
\hline Cell densities & EFM - SPC & SPC - FCM & EFM - FCM \\
\hline 1000 & ND (EFM) & $0.46(0.67)^{*}$ & ND (EFM) \\
10000 & $0.11(0.92)^{*}$ & $0.17(0.88)^{*}$ & $0.13(0.90)^{*}$ \\
\hline
\end{tabular}

A comparison of the advantages and disadvantages of each technique is presented in Table 4 and the quantitative detection limit of each technique is shown in Fig. 4. The concentration of cells by filtration can be combined with most techniques but not with FCM, whereas cultures can be grown independently with a liquid sample or using filtration when needed to analyze a large volume of liquid. Therefore, EFM and SPC are only applicable to filterable samples. For any microscope, the detection limit corresponds to the detection of a single cell per microscopic field, which generally requires the presence of at least $5 \times 10^{3}$ cells $\mathrm{cm}^{-2}$ on the filter (at a magnification of $\times 1250$ ), though this limit may vary depending on the magnification coefficient of the microscope and should be lower for larger organisms (Table 5). In addition, in contrast to culture methods and SPC, the accuracy of microscopic counts is dependent on the number of cells per microscopic field and on the distribution of cells on the membrane since counts are determined from the examination of a very small area on the membrane, and an assumption is made that cells are homogeneously distributed (Lebaron et al. 1994). Furthermore, microscopy is not adapted to the detection of rare events and this limitation is amplified when targeted cells are diluted within a background of non-targeted cells. Indeed, targeted cells cannot be detected when they account for, as in the case of some pathogens, $<0.01 \%$ of total cells because non-targeted cells cover the entire surface of the filter and may mask the fluorescence of targeted cells.

With fewer than 100 cells $\mathrm{ml}^{-1}$ it is difficult to ensure the reproducibility of samples for FCM and other techniques. In this case, it is necessary to examine a large volume of samples to obtain a statistically significant estimate of cell density (Pinder et al. 1990). However, analysis of large volumes is often difficult or even impossible. For instance, if

Table 4. Advantages and disadvantages of culture, SPC, FCM and EFM. +: Applicable; -: non-applicable; +/-: applicable with limits

\begin{tabular}{lcccc|}
\hline & Culture & SPC & FCM & EFM \\
\hline Rare events & + & + & - & - \\
Volume $>1 \mathrm{ml}$ & + & + & - & + \\
Concentration & + & + & - & + \\
Accuracy of counts & + & + & + & $+/-^{\mathrm{a}}$ \\
Rapidity & - & + & $+^{\mathrm{a}}$ & + \\
Mulitparameters & - & + & + & + \\
Total counts & - & + & + & + \\
Viable or active cell counts & + & + & + & + \\
Isolation & + & $+/-^{\mathrm{b}}$ & - & $+/-^{\mathrm{b}}$ \\
Analysis of & & & & \\
non-filtrable products & + & - & $+/-$ & - \\
& & & & \\
aD Depending on cell concentration & & & \\
by subsequent incubation of the membrane on a culture \\
medium
\end{tabular}

$1 \mathrm{ml}$ of sample containing 100 targeted bacteria is passed through the cytometer at a flow rate of $40 \mu \mathrm{l}$ $\mathrm{min}^{-1}$, then $25 \mathrm{~min}$ is required to detect 100 events. Although FCM is popular for rapid and accurate counting of bacterial cells in water, the detection of bacterial cells requires the detection of at least 100 cells. Consequently, the application of this technique depends on

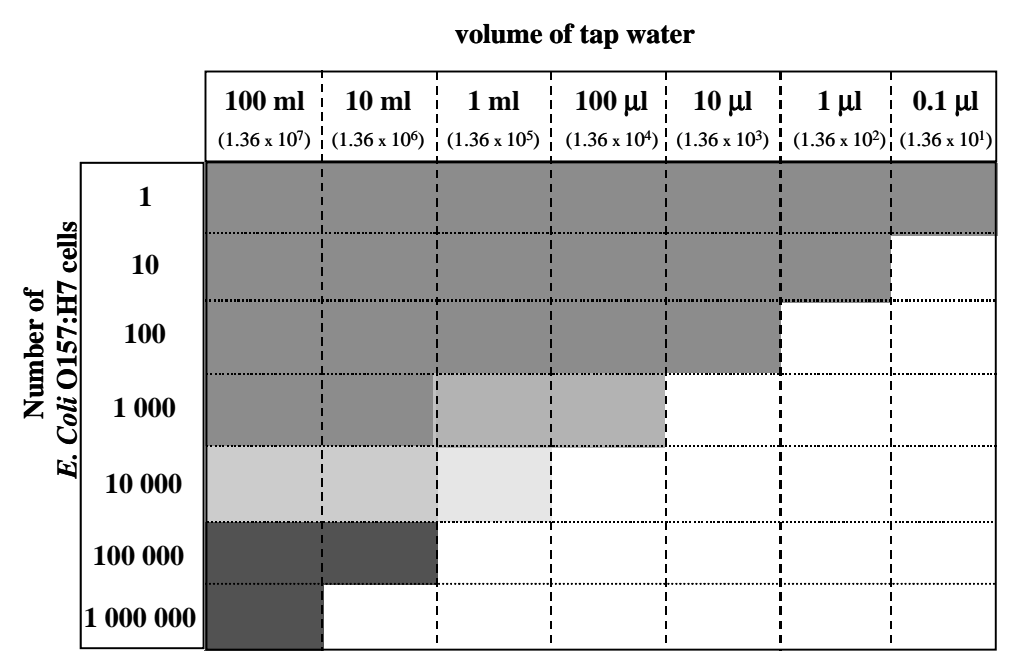

EFM

$\square$ SPC

$\mathrm{SPC}+\mathrm{FCM}$

$\mathrm{SPC}+\mathrm{EFM}$

$\mathrm{SPC}+\mathrm{FCM}+\mathrm{EFM}$

Not tested because these samples could be analyzable by all instruments by the use of dilution or filtration
Fig. 3. Domains of application of epifluorescence microscopy (EFM), flow cytometry (FCM) and solidphase cytometry (SPC) depending on both the absolute number of labeled Escherichia coli cells and the volume of tap water analyzed. For each volume, the number of non-labeled cells present in the tap water is reported in parentheses. Each area represents the domain of application of an instrument 


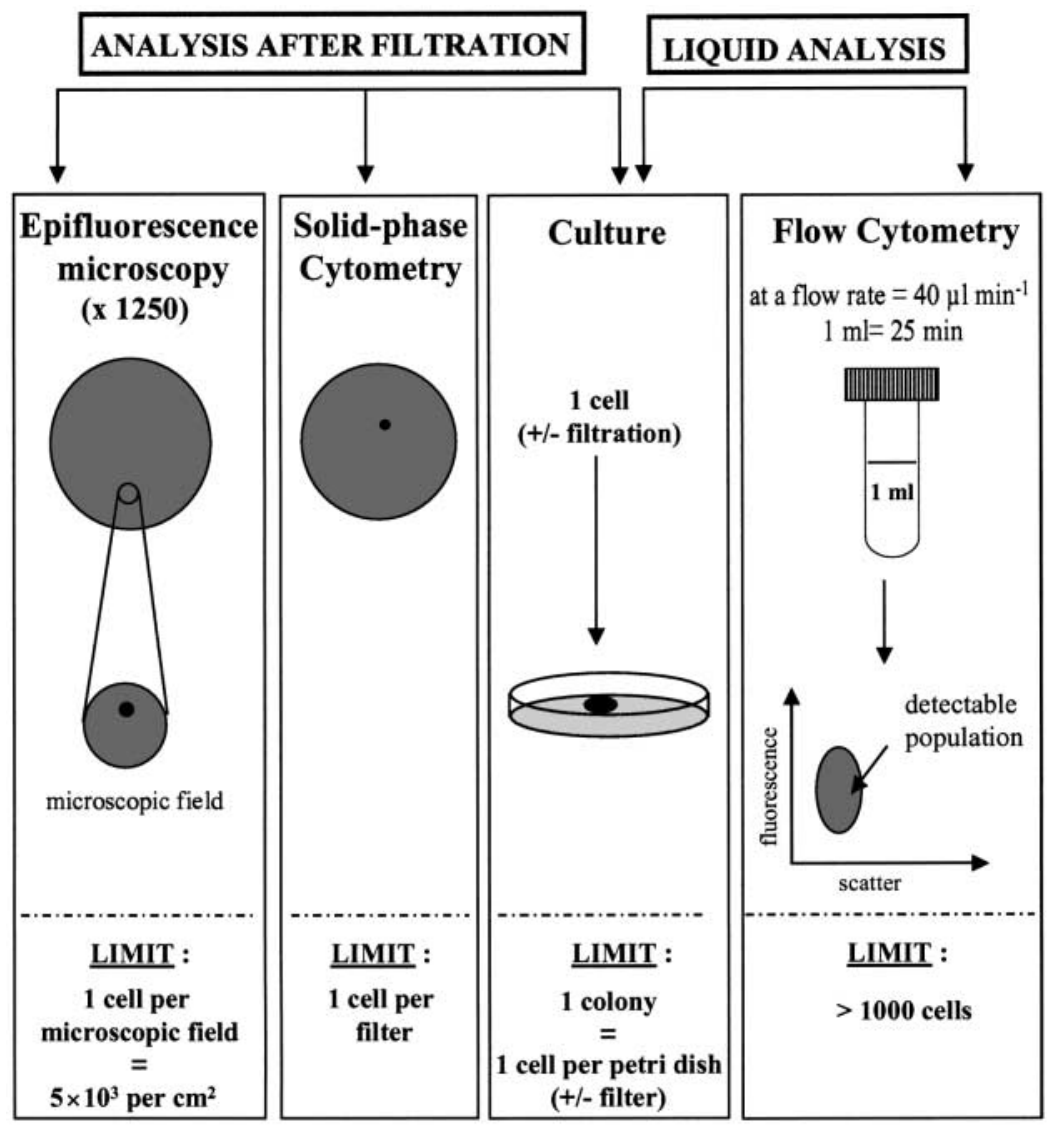

Fig. 4. Quantitative limits of EFM, FCM, SPC and traditional plate count techniques in water samples

the concentration of cells in the sample to be analyzed. If a cell concentration falls below 500 cells ml ${ }^{-1}$ and a mean flow rate of $40 \mu \mathrm{min}^{-1}$ is used, the time of analysis may be $>5$ min leading to difficulties in discriminating the cellular population on the cytogram.

Unlike traditional culture methods, SPC allows rapid detection of total as well as active cells when combined with physiological probes (Catala et al. 1999, Reynolds \& Fricker 1999, Parthuisot et al. 2000). Moreover, this technique is the only direct method appropriate to the detection of rare events that provides the same detection limit as plate count techniques. The main advantage of traditional culture methods is the ability to isolate cells for further physiological and genetic analyses. Although this isolation is more difficult with direct techniques using filtration, it may be possible with EFM and SPC by incubating the filters at the surface of a solid medium. However, subsequent culture depends on the toxicity of the dyes used for staining and detecting the cells since most of these dyes have toxic effects on the bacterial metabolism (Ullrich et al. 1996). Flow cytometers equipped with cell sorters may also permit the sorting of a specific population and its subsequent culture and isolation, but this procedure is time-consuming and cannot be applied routinely.

Most of the techniques based on the use of fluorescent probes are adapted to multiparametric analysis. They do not rely on the measurement of a single property but rather on a correlation between different measurements. For instance, this multiparametric approach may be of great interest to analyze the physiological state of specific individual cells combining physiological and taxonomic (i.e., antibodies) probes but it has received little attention up to now because it concerns the detection of rare pathogenic bacteria not detectable by FCM and EFM. The ChemScan ${ }^{\mathrm{TM}}$ cytometer could provide a new and appropriate tool for this kind of application. One of the main limitations to this approach is probably the single wavelength of excitation available on this cytometer, which limits the combination of fluorochromes.

The main advantage of SPC, based on the scanning device, is that it is possible to detect a single cell on the total surface of the filter. In contrast with EFM, this minimum detection limit of SPC allows a reduced volume of sample to be filtered and, thus, the proportion of non-targeted cells. Consequently, it also reduces the risk of membrane blockage when samples containing non-cellular particles are filtered. Furthermore, the detection limit of this instrument is similar to that of the traditional plate count technique combined with filtration.

The data presented in this study have shown the potential of SPC for the rapid detection of low numbers of Escherichia coli O157:H7 cells in natural water. In fact, classical methods of detection of E. coli O157:H7

Table 5. Detection limits of EFM depending on the magnification factor used. Calculations are done for a $25 \mathrm{~mm}$ diameter membrane, an effective filtration area of $20 \mathrm{~mm}$ diameter and an additional magnification factor of 1.25

\begin{tabular}{|lcccc|}
\hline Objective & $\times 10$ & $\times 20$ & $\times 40$ & $\times 100$ \\
\hline Magnification & $\times 125$ & $\times 250$ & $\times 500$ & $\times 1250$ \\
$\begin{array}{l}\text { Microscopic field } \\
\text { diameter (mm) }\end{array}$ & 1.6 & 0.8 & 0.4 & 0.16 \\
$\begin{array}{l}\text { Microscopic field } \\
\left.\text { surface (mm }{ }^{2}\right)\end{array}$ & 2.01 & 0.503 & 0.126 & 0.020 \\
$\begin{array}{l}\text { No. of microscopic fields } \\
\text { per membrane }\end{array}$ & 156 & 625 & 2500 & 15625 \\
\hline
\end{tabular}


require selective and confirmational enrichments that can take 2 or $3 \mathrm{~d}$ and require a final biochemical and serological characterization that can take up to $4 \mathrm{~d}$. Actually, there are several commercial E. coli O157:H7 detection kits, but most of them require lengthy enrichments to achieve comparable sensitivities (Czajka \& Batt 1996). SPC has been recently applied to the sensitive detection of $E$. coli O157:H7 in food using an immunomagnetic separation step (Pyle et al. 1999). The instrument offers the advantage of a rapid and accurate quantification of bacterial cells within a large range of cell densities. Its application to the detection of rare pathogens (including bacteria, protozoa and phytoplankton) in aquatic samples and to sterility assessment opens new perspectives in the domain of water quality control but also in the field of microbial ecology for the study of specific populations. The ChemScan ${ }^{\mathrm{TM}}$ system has already been applied to the rapid detection of viable cells in the pharmaceutical industry (Wallner et al. 1997) and to the detection of Cryptosporidium parvum in drinking water (Reynolds et al. 1999, Rushton et al. 2000). As for E. coli O157:H7, detection of protozoa such as C. parvum and Giardia lamblia is often long and laborious and the use of SPC offers new perspectives for their detection in water (Reynolds \& Fricker 1999).

In conclusion, the range of applications of these 3 techniques was quite variable. In microbial ecology, the use of FCM for enumeration of total or active cells seems to be suitable for global studies, whereas SPC may allow analysis of the spatial and temporal dynamics of specific populations present at low densities and within a background of nonspecific cells. These applications require the use of fluorescent taxonomic probes such as antibodies combined with physiological probes to assess both specificity and viability of the cells. SPC could be a good alternative to laborious and time-consuming culture methods for the detection and enumeration of a wide variety of specific bacteria or protozoa in natural samples.

Acknowledgements. We thank Frank Laurent, Jean-Louis Drocourt and Philippe Cornet for helpful discussions and Marc Troussellier for helpful comments concerning the statistical comparison of results. This work was supported by contract ELOISE-CT960047 from the European Community. The FACS-Calibur flow cytometer was funded by CNRS-INSU and by contract ELOISE-CT960047. The ChemScan ${ }^{\mathrm{TM}}$ cytometer was partly funded by the Région Languedoc-Roussillon.

\section{LITERATURE CITED}

Amann RI, Ludwig W, Schleifer KH (1995) Phylogenetic identification and in situ detection of individual microbial cells without cultivation. Microbiol Rev 59:143-169

Anderson DM, Kulis DM, Keafer BA, Berdalet E (1999) Detec-

Editorial responsibility: James Hollibaugh,

Athens, Georgia, USA tion of the toxic dinoflagellate Alexandrium fundyense (Dinophyceae) with oligonucleotide and antibody probes: variability in labelling intensity with physiological condition. J Phycol 35:870-883

Catala P, Parthuisot N, Bernard L, Baudart J, Lemarchand K, Lebaron P (1999) Effectiveness of CSE to counterstain particles and dead bacterial cells with permeabilised membranes: application to viability assessment in water. FEMS Microbiol Lett 178:219-226

Czajka J, Batt CA (1996) A solid phase fluorescent capillary immunoassay for the detection of Escherichia coli O157:H7 in ground beef and apple cider. J Appl Bacteriol 81:601-607

Joux F, Lebaron P (2000) Use of fluorescent probes to assess physiological functions of bacteria at single-cell level. Microb Infect 2:1523-1535

Kell DB, Kaprelyants AS, Weichart DH, Harwood CR, Barer MR (1998) Viability and activity in readily culturable: a review and discussion of the practical issues. Antonie Van Leeuwenhoek 73:169-187

Lebaron P, Troussellier M, Got P (1994) Accuracy of epifluorescence microscopy counts for direct estimates of bacterial numbers. J Microbiol Methods 19:89-94

Lebaron P, Parthuisot N, Catala P (1998) Comparison of blue nucleic acid dyes for flow cytometric enumeration of bacteria in aquatic systems. Appl Environ Microbiol 64: 1725-1730

McFeters GA, Yu FP, Pyle BH, Stewart PS (1995) Physiological assessment of bacteria using fluorochromes. J Microbiol Methods 21:1-13

Mignon-Godefroy K, Guillet JC, Butor C (1997) Laser scanning cytometry for detection of rare events. Cytometry 27: 336-344

Parthuisot N, Catala P, Lemarchand K, Baudart J, Lebaron P (2000) Evaluation of ChemChrome V6 for bacterial viability assessment in waters. J Appl Microbiol 89:370-380

Pinder AC, Purdy PW, Poulter SAG, Clark DC (1990) Validation of flow cytometry for rapid enumeration of bacterial concentrations in pure cultures. J Appl Bacteriol 69: 92-100

Porter J, Deere D, Hardman M, Edwards C, Pickup R (1997) Go with the flow: use of flow cytometry in environmental microbiology. FEMS Microbiol Ecol 24:93-101

Pyle BH, Broadaway SC, McFeters GA (1999) Sensitive detection of Escherichia coli O157:H7 in food and water by immunomagnetic separation and solid-phase laser cytometry. Appl Environ Microbiol 65:1966-1972

Reynolds DT, Fricker CR (1999) Application of laser scanning for the rapid and automated detection of bacteria in water samples. J Appl Bacteriol 86:785-795

Reynolds DT, Slade RB, Sykes NJ, Jonas A, Fricker CR (1999) Detection of Cryptosporidium oocysts in water: techniques for generating precise recovery data. J Appl Microbiol 87: 804-813

Rushton P, Place BM, Lightfoot NF (2000) An evaluation of a laser scanning device for the detection of Cryptosporidium parvum in treated water samples. Lett Appl Microbiol 30: 303-307

Ullrich S, Karrash B, Hoppe HG, Jeskulke K, Mehrens M (1996) Toxic effects on bacterial metabolism of the redox dye 5-cyano-2,3-ditolyl tetrazolium chloride. Appl Environ Microbiol 62:4587-4593

Wallner G, Tilmann D, Haberer K, Cornet P, Drocourt JL (1997) The Chem $\operatorname{Scan}^{\mathrm{TM}}$ system: a new method for rapid microbiological testing of water. Eur J Parenter Sci 2: 123-126

Submitted: March 15, 2001; Accepted: August 29, 2001

Proofs received from author(s): September 18, 2001 